\title{
Antagonistic Potential of Trichoderma harzianum against Rhizoctonia solani Causing Banded Leaf and Sheath Blight of Maize
}

\author{
Shweta Priya* and J.P. Upadhyay \\ Department of Plant Pathology, Dr. Rajendra Prasad Central Agricultural University Pusa \\ Samastipur- 848 125, Bihar, India \\ *Corresponding author
}

\section{A B S T R A C T}

The basic aim of the investigation was to screen the potential of Trichoderma harzianum for bio suppression of Rhizoctonia solani f. sp. sassaki, the causal agent of banded leaf and sheath blight of maize which is one of the most destructive diseases of Bihar. The disease severity ranging from 30.30 to 80.46 per cent and gaining the economic importance now a day. Maize (Zea mays L.) is one of the most important cereal crops in the world agricultural economy as food, feed and industrial products. It is a miracle C4 crop and has a very high yield potential. There is no other cereal, which has such an immense potentiality and thus is rightly called queen of cereals. In India, maize is grown in almost all the states. It is fourth in area next to rice, wheat, and sorghum, but third in production. It is not only utilized for direct human consumption but also for livestock and poultry feed. Trichoderma harzianum was evaluated for its antagonistic potential against Rhizoctonia solani $\mathrm{f}$. sp. sasakii in vitro condition by employing dual culture technique. The outcome of testing revealed that in dual culture, after 72 hours of incubation, Trichoderma started to overgrew the pathogen colony and in 144 hours Trichoderma fully covered (100\%) the pathogen colony and totally inhibited sclerotial formation. The mechanism of antagonism was hyphal coiling and penetration of the hyphae of Trichoderma in the hyphae of host fungus.

\section{Introduction}

The increasing awareness to pesticides related hazards had led to adoption of alternative methods for disease management which is eco-friendly and in this context biological control is a good option. Biological control of plant diseases maintain the biological balance within the soil ecosystem and offers a powerful means to improve the soil health and increase the productivity of plant by suppression and destruction of pathogen inoculum. It is an important approach for plant disease management under changing habitat and commercialization of agriculture. In recent years attempts were also made to use consortium of bio control organism to get persistent control of plant pathogens. Antagonistic fungi especially Trichoderma species have been widely used against number of phytopathogens particularly soil borne fungi such as Rhizoctonia species which causes soil borne diseases to a wide range of crops. Banded Leaf and Sheath Blight (BLSB) of maize is one of the destructive diseases of maize caused by 
Rhizoctonia solani f. sp. sasakii (Kuhn). Rhizoctonia solani is wide spread in tropical and subtropical region of the world and once established in the field the fungus often remains indefinitely. Sclerotia of $R$. solani are known to survive several years in the soil. In this disease, crop rotation and tillage practices have little effect on the disease severity. Integrated Pest Management (IPM) strategy for its management is crucial. Biological control appears to be the best solution for long term sustainability and effective management for this soil borne pathogen. Knowing these factors the present investigation was done to assess the potential of Trichoderma harzianum against Rhizoctonia solani f. sp. sasakii in vitro.

\section{Materials and Methods}

Isolation and purification of phytopathogen and bioagent

Rhizoctonia solani was isolated from the diseased maize leaf infected with banded leaf and sheath blight collected from the experimental farm of Tirhut College of Agriculture, Dholi, Muzaffarpur and bioagent Trichoderma harzianum from soil was isolated and purified by serial dilution plate method (Warcup, 1950, 1960) by using peptone dextrose rose bengal agar medium and potato dextrose agar medium.

\section{Antagonism}

The antagonistic activity of Trichoderma harzianum against Rhizoctonia solani f. sp. sasakii, the incitant of Banded leaf and sheath blight disease of maize was studied by dual culture technique (Morton and Stroube, 1955). They were cultured on PDA plates for 72 hours. A $5 \mathrm{~mm}$ disc of Trichoderma was inoculated on the Potato Dextrose Agar medium on one side of petriplate aseptically and $5 \mathrm{~mm}$ disc of $R$. solani was inoculated at the opposite side in the same plate in such a way that the discs were $4 \mathrm{~cm}$ apart from each other. The plates were then incubated at $28^{\circ} \mathrm{C}$ for 6 days. Antagonisms were apparent when sporulating Trichoderma started over growing on the pathogen colony which was noted at 24 hours interval. Based on observation percentage inhibition was calculated by following formula.

Percentage Inhibition $(\mathrm{PI})=\frac{\mathrm{C}-\mathrm{T}}{\mathrm{C}}$

Where,

$\mathrm{C}=$ Radial growth of pathogen in control plate.

$\mathrm{T}=$ Radial growth of pathogen in dual culture.

\section{Mycoparasitism}

The slides were prepared from intermingling zone of dual culture in 0.1 per cent cotton blue. Detailed study was done to observe hyphal interaction i.e., coiling, penetration. Photomicrographs were taken for mode of parasitism at high power of magnification.

\section{Results and Discussion}

\section{Symptoms of disease}

Banded leaf and sheath blight (BSLB) disease of maize is caused by Rhizoctonia solani f. sp. sasakii (Kuhn.) is the most devastating disease of maize. It has now become a wide spread disease and had been reported to cause $(31.9 \%)$ reduction in grain yield in maize cultivar with disease severity level up to 87.3 per cent (Lal et al., 1980). In India, the annual loss of maize production due to BLSB had been estimated upto 13.2 per cent (Payak and Sharma, 1985). Characteristics symptoms 
include concentric bands on infected leaves and sheath that are discoloured, brown, tan or grey in colour. Typically disease develops on the first and second leaf sheath above the ground and eventually spread to the ears causing ear rot which is characterized by light brown cottony mycelium on the ear and the presence of small round black sclerotia and its cobs dry prematurely.

Characters of Rhizoctonia solani f. sp. sasakii and Trichoderma harzianum

The identity of pathogen was established on the basis of cultural and morphological characters. The colony of Rhizoctonia solani was fast growing on PDA. It produces white to deep brown mycelium and dark brown irregular sclerotia. Mycelium was septate, multinucleate abundantly branching rather stout mycelium. Hyphae were 4-15 m wide and tended to branch at right angle. A septum near each branch with a slight constriction at the point of branching was observed and Colonies of Trichoderma harzianum grow rapidly and mature in 5days. On PDA colonies are wooly and become compact. Hyphae are septate, hyaline and conodiophores are hyaline and branched. Phialides are flask shaped and inflated at the base. Conidia are mostly green in colour. The symptoms and morphological characters observed in the present investigation had also been recorded and described by several workers (Singh and Sharma 1976; Maiti 1978).

\section{Antagonism}

After 24 hours of incubation clear radial growth of $R$. solani and T. harzianum was observed with 20 and $35 \mathrm{~mm}$ diameter respectively whereas diameter of Rhizoctonia in control was $34 \mathrm{~mm}$. Examination of the extent of fungal growth in dual culture revealed that the first apparent contact between hyphae of both fungi had occurred after 48 hours of inoculation at that time hyphae of Rhizoctonia was grown up to 35 $\mathrm{mm}$ diameter. Various other workers also reported similar observation (Elad et al., 1982; Pan and Jash 2009). After 72 hours of incubation, Trichoderma started to overgrew the pathogen colony and in 144 hours Trichoderma fully covered (100 \%) the pathogen colony and totally inhibited sclerotial formation. This can be easily cleared by (Table 1). In microscopic view, mode of antagonism observed was coiling and penetration (Plate 1). The process of coiling initiated first, thereafter simultaneously the mycoparasite penetrates the host. Similar process of coiling and penetration was also observed by Agarwal and Kotasthane (2010).

Table.1 Antagonistic activity of Trichoderma harzianum against Rhizoctonia solani f. sp. sasakii

\begin{tabular}{|c|c|c|c|c|c|}
\hline \multirow{2}{*}{ Hours } & \multicolumn{2}{|c|}{$\begin{array}{l}\text { Colony dia. (mm) in dual } \\
\text { culture }\end{array}$} & \multirow{2}{*}{$\begin{array}{l}\text { Colony dia. } \\
(\mathrm{mm}) \text { of } \\
R . \text { solani in } \\
\text { monoculture }\end{array}$} & \multirow{2}{*}{$\begin{array}{c}\text { Inhibition of } \\
\text { mycelial growth of } \\
R . \text { solani } \\
(\%)\end{array}$} & \multirow{2}{*}{$\begin{array}{l}\text { Overgrowth of } T \text {. } \\
\text { harzianum on } \\
\text { colony of } R \text {. solani } \\
(\%)\end{array}$} \\
\hline & T. harzianum & R. solani & & & \\
\hline 24 & 35 & 20 & 34 & - & - \\
\hline 48 & 55 & 35 & 65 & - & - \\
\hline 72 & 60 & 35 & 75 & $53.73(47.12)^{* *}$ & $14.40(22.25) * *$ \\
\hline 96 & 70 & 35 & 90 & $61.47(51.65)$ & $43.24(41.16)$ \\
\hline 120 & 85 & 35 & 90 & $61.47(51.65)$ & $86.35(87.90)$ \\
\hline 144 & 90 & 35 & 90 & $61.47(51.65)$ & $100(90)$ \\
\hline SEM & 0.31 & 0.17 & 0.17 & 0.18 & 1.33 \\
\hline $\mathrm{CD}$ at $5 \%$ & 1.01 & 0.53 & 0.53 & 0.61 & 4.35 \\
\hline $\mathrm{CV}$ & 0.92 & 0.91 & 0.40 & 0.64 & 4.21 \\
\hline
\end{tabular}

** Values in parentheses are Arcsin $\sqrt{\text { Percentage transformation }}$ 
Table.2 Showing sclerotia formation during successive growth stages of $R$. solani in mono and dual culture with T. harzianum

\begin{tabular}{|l|c|c|}
\hline \multirow{2}{*}{ Hours } & \multicolumn{2}{|c|}{ No. of sclerotia } \\
\cline { 2 - 3 } & In monoculture & \multicolumn{1}{c|}{ In dual culture } \\
\hline 72 & 22 & Aggregation of mycelium \\
\hline 96 & 40 & No sclerotia formation \\
\hline 120 & 55 & No sclerotia formation \\
144 & 68 & No sclerotia formation \\
168 & 0.5 & No sclerotia formation \\
SEM & 1.8 & - \\
\hline CD at $5 \%$ & 2.1 & - \\
\hline CV & & - \\
\hline
\end{tabular}

Fig.1 Mode of antagonism between T. harzianum and $R$. solani f. sp. sasakii

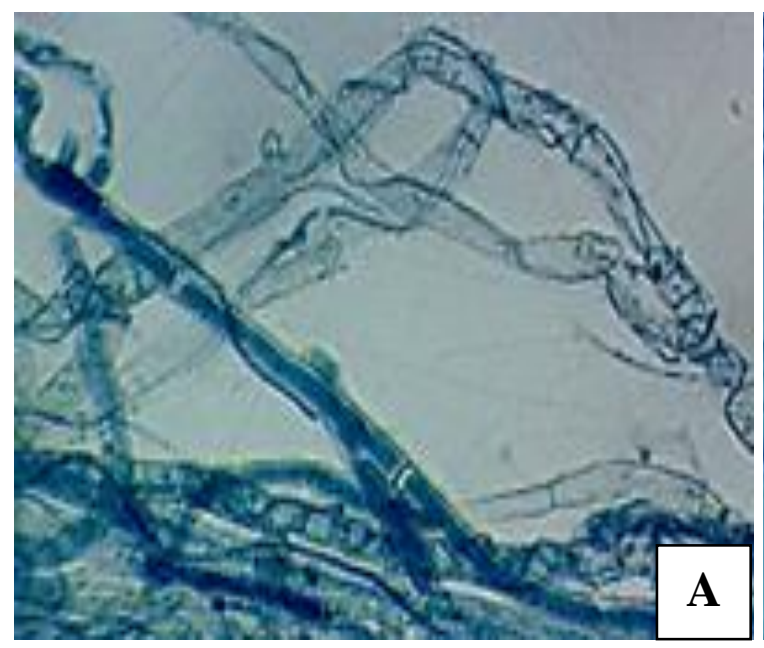

(A) Coiling and

In monoculture aggregation of mycelium occurred in Rhizoctonia solani after 72 hours of incubation. After 96 hours 22 sclerotia were formed and after 120, 144, 168 hours 40, 55 and 68 sclerotia were formed but in dual culture with Trichoderma aggregation of mycelium occurred after 72 hours but sclerotia formation in dual culture was completely inhibited. (Table 2) T. harzianum completely overgrew the hyphal colony of $R$. solani f. sp. Sasakii (Fig. 1).

In the present investigation Trichoderma harzianum in dual culture inhibited mycelial growth of $R$. solani up to 61 per cent which corroborates with the findings of Mello and

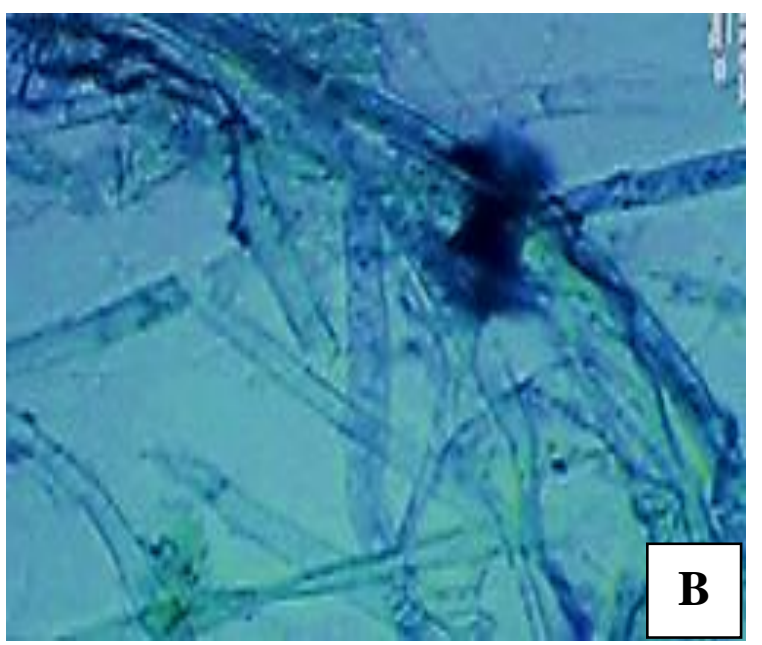

(B) Penetration

Faull, 2000; Agarwal and Kotasthane, 2007; 2010. Sclerotia formation was totally inhibited in dual culture in the present investigation. Successful biological control of $R$. solani by infesting field with culture of $T$. harzianum had been reported by (Back man et al., 1975).

Further investigation with the potential isolate of Trichoderma may help to explore it for control of $R$. solani and diseases caused by it.

\section{Acknowledgement}

I am very thankful to department of plant pathology, Dr. Rajendra Prasad Central 
Agricultural University for providing me all the facilities for sincerely conducting of my post graduate research work.

\section{References}

Agarwal, T., and Kotashthane, A.S. 2010. Mycoparasitism AFLP characterisation and effectiveness of Trichoderma species isolated from Chhattishgarh in Central India against Rhizoctonia solani infecting rice. Indian J. Mycol. and Pl. Pathol. 40: 532-538.

Backmann, P. A., and Rodriguez-kabana, R. 1975. A system for growth and delivery of biological control agents to the soil. Phytopathology 65: 819-821.

Elad, Y., Chet, I. and Henis, Y. 1982. Degradation of plant pathogenic fungi by Trichoderma harzianum. Can. J. Microbiol. 28: 719-725.

Lal, S., Baruah, P. and Butchaiah, K. 1980. Assessment of yield losses in maize cultivars due to banded sclerotial disease. Indian Phytopath. 33: 440-443.

Maiti, S., 1978. Two ear rots of maize from India. Plant Dis. Rep 62: 1074-1076.

Mello, I.S., De and Fall, J.L. 2000. Parasitism of Rhizoctonia solani by strains of Trichoderma spp. Scientia Agricola 57: 55-59.

Morton, D. T., and Stroube, N. H. 1955. Antagonistic and stimulatory effect of microorganism upon Sclerotium rolfsii. Phytopathology 45: 419-420.

Pan, S., and Jash, S. 2009. Variability in sclerotial antagonism of mycoparasitic Trichoderma species against Rhizoctonia solani and Sclerotium rolfsii. Indian J. Mycol. and Pl. Pathol. 39: 409-415.

Payak, M. M., and Sharma, R.C. 1985. Maize diseases and approaches to their management in India. Trop. Pest. Manage. 31: 302-310.

Warcup, J. H., 1950. The soil plate method for isolation of fungi from soil. Nature 166: $117-118$.

\section{How to cite this article:}

Shweta Priya and Upadhyay, J.P. 2017. Antagonistic Potential of Trichoderma harzianum against Rhizoctonia solani Causing Banded Leaf and Sheath Blight of Maize. Int.J.Curr.Microbiol.App.Sci. 6(10): 886-890. doi: https://doi.org/10.20546/ijcmas.2017.610.106 